\title{
SPORTS ACTIVITIES FOR PEOPLE WITH DOWN SYNDROME
}

\author{
Mihai Constantin Răzvan BARBU, Amalia Raluca Stepan, Dumitru BARBU, Cătălin \\ FORȚAN, Luminița BRABIESCU CĂLINESCU, Marian Alexandru COSMA
}

\author{
University of Craiova, Faculty of Physical Education and Sport, Craiova \\ email: mihai.barbu@edu.ucv.ro
}

\section{https://doi.org/10.52846/jskm/37.2021.1.5}

\section{Abstract:}

The field of physical exercise has always existed. But the way of practice was different, evolving from a purely empirical aspect (when motor acts required for human existence were practiced) to the current aspect of sports practice on a scientific basis. Despite their genetic disorder, individuals with Down syndrome are interested in physical activities aiming to increase their quality of life by adapting sports to their own potential. One of the most important recovery ways that individuals with Down syndrome undoubtedly have at their disposal is sport. The passion and determination that these people show every day of training have contributed to the shaping of many sports champions, thus managing to achieve independence, a difficult target for people with intellectual disabilities. Through this paper we aim to shed some light on this condition that is facing a growing number of people and to present a short study where a number of legal representatives of people with Down syndrome have been involved, as well as to better understanding the role that sports can play in supporting these people. This survey is part of a larger project carried out by the SPADS European Consortium in which a Romanian parents association, ALDO-CET is a member and the Italian organization ASD RUNNING MATERA is the coordinator.

Keywords: Down Syndrome, sports, physical abilities, development.

\section{Introduction}

People with Down syndrome always encounter preconceptions, which extend to those around them. Sometimes the family is stigmatized. It is most often said that fate was unjust. The most unfair thing is that people ask themselves "how to knowingly give birth to a child with Down syndrome?" People with Down syndrome live with their parents, or in single-parent families. 3.1 percent are institutionalized. The causes of Down syndrome are still unknown.

Each person is unique, as is the dynamics of the family to which he/she belongs. Studies show that $97 \%$ of siblings express feelings of pride and $88 \%$ say they have become better people thanks to a sibling with Down syndrome or intellectual disability (Skotko, Levine\& Goldstein, 2011, Shivers \& Dykens, 2017).
Most parents try to give the same attention to all the children in family. It is required for all people and all aspects of society to support the inclusion of people with Down syndrome in development policies. Many might imagine that sport cannot be practiced by a person with certain limitations, but fortunately, adapted sport provides opportunities for socialization, discovery, and acceptance of human performance, even for those with special abilities. Practicing adapted sports and implementing them in groups train children to communicate, to become more sociable and to overcome their psychological barriers.

Through hard work and dedication, these wonderful people turn the clumsiness of a "cannot" into safe steps to victory. A victory that people with Down Syndrome manage to turn it into a victory of inclusion through their huge capacity for love.

Down syndrome in children 
Down syndrome has become one of the most common conditions of the century affecting an increasing number of children.

This condition can occur during any conception, but the birth rate is higher in mothers above 35 years of age. Unlike ordinary people who have 46 chromosomes, people with Down syndrome have an extra one within the pair of chromosomes 21. In other words, the person has 47 chromosomes instead of 46 (Daniels, Finning, Martin, \& Massey, 2009).

Flattened face, small head and short neck, a flat nasal bridge, small mouth, as well as mandible, mostly a protruding tongue, excess skin on the nape of the neck, eyelids tilted upwards, small ears or unusually shaped are just a few among the obvious signs. Children Down syndrome have low muscle tone, muscle hypotonia being present in $80 \%$ of cases in new-borns and infants. Small white spots on the iris, called Brushfield spots, are present in these people. Intellectual disability is another problem of these children varying from case to case, so that intellectual issues can be mild, moderate or severe.

Half of all new-borns with Down syndrome have a congenital heart defect. Genetic abnormalities, including Trisomy 21 , can be detected in the first months of pregnancy without endangering the mother and fetus.

Screening tests can be done to show the risk of pregnancy with Down syndrome and diagnostic tests, for example in the case of prenatal testing by karyotype from chorionic villi or fetal cells from amniotic fluid can determine with certainty if the fetus is affected and the type of Down syndrome (Millar, Fernhall, \& Burkett, 1992).

\section{Clinical features of Down syndrome}

Here are the clinical signs of individuals with Down syndrome:

- characteristic physical features;

- changes in physical and intellectual development;

- malformations of some organs (heart malformations are the most common);

- low muscle tone;

- lower waist and weight than other children.
Babies with Down syndrome show the following signs:

- flattened facial features;

- brachycephalic head;

- round and flat face;

- small ears with an atypical shape;

- shorter and wider hands;

- shorter neck;

- bulging tongue;

- eyes tilted upwards;

- muscle weakness.

A baby born with Down syndrome may have a normal birth weight, but its development will be slower than that of an ordinary baby. Motor development is even slower than the intellectual one.

Mental manifestations of Down syndrome may also occur, such as:

- impulsive behaviour;

- weaker judgment;

- attention deficit;

- slower learning skills.

Children with Trisomy 21 are calm, obedient, affectionate, love the entourage, music, joy (Potter, 1991). Life expectancy has increased quite a lot during recent years, reaching about 65 years. About seven million individuals in the world live with this syndrome.

In absolutely all cases of developmental delay, early intervention is vital. The earlier the therapies for physical and intellectual recovery begin, the greater the chances of progress.

In the first stage, a proper analysis of the child's abilities is needed to draw up an adequate motor development and intervention plan.

Occupational therapy, behavioural therapy, speech therapy, physical therapy are among the forms of therapy used. Beyond these, which have now become "classic" methods, art therapy, animal therapy (such as hippotherapy - with horses and onotherapy with donkeys) or movement exercises in water (hydrotherapy) bring visible improvements to people with Down syndrome. Sensory stimulation and the development of fine motor skills are also aspects that the therapist and family must enforce. 
A peculiarity of this condition is that individuals with Down syndrome have social skills, unlike other forms of developmental delay. For this reason, it is extremely important that the therapeutic intervention aims at the development of independence and verbal communication of the child and enhances the artistic skills specific to individuals with Down syndrome.

The family has a vital role in the life of the little one diagnosed with Down syndrome, just as it has in the life of any other human being. It is extremely important that the parents do not feel blamed or abandoned and do not be overwhelmed by feelings of guilt. If the parents are well, the child is wellbeing. They need strength and balance to take care of the child with special needs. Once in a while, the parents also need a separate life from that of the child, in order to restore their inner balance.

The parents should be supported and encouraged to continue the child's therapies and exercises at home. The quality and effectiveness of intervention can only be influenced if parents integrate the application of corrections in their interactions with their children. However, there is also a risk of focusing so much on the "problems" and difficulties of the child or on the therapies and recovery, so that they lose sight of the fact that the little one is not a patient, but above all he/she is their own child, who needs playing, fairy tales, tickling, relaxing walks or "breaking" days, in which "I don't like it" and "I don't want it" to be allowed.

During the life of a child with Down syndrome, the family "sets the tone" in the social environment: a child accepted within the family, cared for, whom the parents do not keep him locked in the house, do not hide him, and do not talk to him in bad words or illness terms will be a grownup accepted by society.

Sport - one of the ways to support people with Down syndrome

Unlike ordinary people who have 46 chromosomes, people with Down syndrome have an extra one within the pair of chromosomes 21. In other words, the person has 47 chromosomes instead of 46 (Daniels,
Finning, Martin, \& Massey, 2009). Children with Down syndrome are also called "children of the sun" for their kindness and enthusiasm. Like any other human being, individuals with Down syndrome have a natural need for movement and dynamic life, even their motor behaviour is subject to specific disorders typified by functional limitations.

One of the non-formal educations that individuals with this condition undoubtedly have at their disposal is sport. The passion and determination that these people show every day of training have contributed to the shaping of many sports champions, thus managing to achieve independence, a difficult target for people with intellectual difficulties.

Through sports, individuals with Down syndrome can learn to cope on their own and to independently carry out their usual activities.

People with intellectual disabilities such as Down Syndrome or other cognitive impairments, need physical activity in the same way as any other person.

Every individual with Down syndrome is different and has own talents. In fact, these people can learn well enough to become active members of the society and to enjoy their own life.

Nothing can be done to prevent this genetic disorder, either before or during pregnancy. No one is guilty.

Every year, more and more children with Down syndrome are enrolled in regular schools and join their siblings and friends in various social activities. Although learning in children with Down syndrome is more challenging, schooling with other children of their age helps them to take care of themselves, to interact with others and to register cognitive progress.

As the child with Down syndrome develops more slowly, the differences between him and others of his age become more and more obvious as the years go by.

However, now days the strong recommendation to enrolment in regular mainstream education is obvious, provided that teachers and parents work together, and the child receives additional support. 
Due to advances in medicine, it has been concluded that the abilities in different areas of people with Down syndrome are moderately delayed, and through different techniques and methodological working with them, they can have a meaningful life.

Based on the up-to-date information, we can conclude that nowadays we can certainly look at the future of children with Down syndrome more optimistic than ever.

Many might imagine that sport cannot be practiced by an individual with certain limitations, but fortunately, adapted sport provides opportunities for socialization, discovery, and acceptance of human performance, even for those with special abilities.

Practicing adapted sports and implementing them in groups train children to communicate, to become more sociable and to overcome their psychological barriers (Barbu, 2004).

There are many types of exercises that can work, but it depends on the individual's abilities and interest.

Special Olympics offer a wide range of individual or team sports. Thus, people with disabilities can play and acquire new skills and can compete with other peers both locally and internationally.

For the safety of an athlete with intellectual disabilities, it is important to previously get medical permission for participation in a sport activity. Both teachers and coaches need to be patient and encourage the athletes through gestures or narrations that can help them to acquire new skills. When the athlete practices with a friend (can also be with the parent), the motivation is stronger. Thus, he will be able to see his progress and improvements, over time.

Like in ordinary people, people with disabilities can participate in mainstream sports as well as in high performance sports. They can be involved in domestic, international, Special Olympics, Paralympics and even Olympics Games (Birrer, 2004). For instance, an athlete in wheelchair participating in the Olympics archery was the one lighting the Olympic flame on the stadium, showing that all athletes are able to enjoy the generous movement of Olympism.

Method

This survey aims to collect the opinions of people with Down syndrome (DS) about their involvement in sports activities. The aim is to communicate your views on this subject to sports specialists, in order to ensure that inclusion activities through sports are designed taking into account the views of people with DS and their relatives.

The survey was conducted on a number of 110 respondents, this preliminary study is part of a project for people with Down syndrome coordinated by the A.S.D. RUNNING MATERA, project that is developed between January 1, 2021 and December 31, 2022.

As this questionnaire aims to collect the opinions of the relatives of people with Down syndrome about their involvement in sports activities, the first question aimed to establish the people who complete the questionnaire.

As expected, over $77 \%$ of respondents are represented by mothers, in an equal proportion of $8 \%$ by fathers or educators, and siblings or personal assistants occupy the last places with percentages below $5 \%$. 


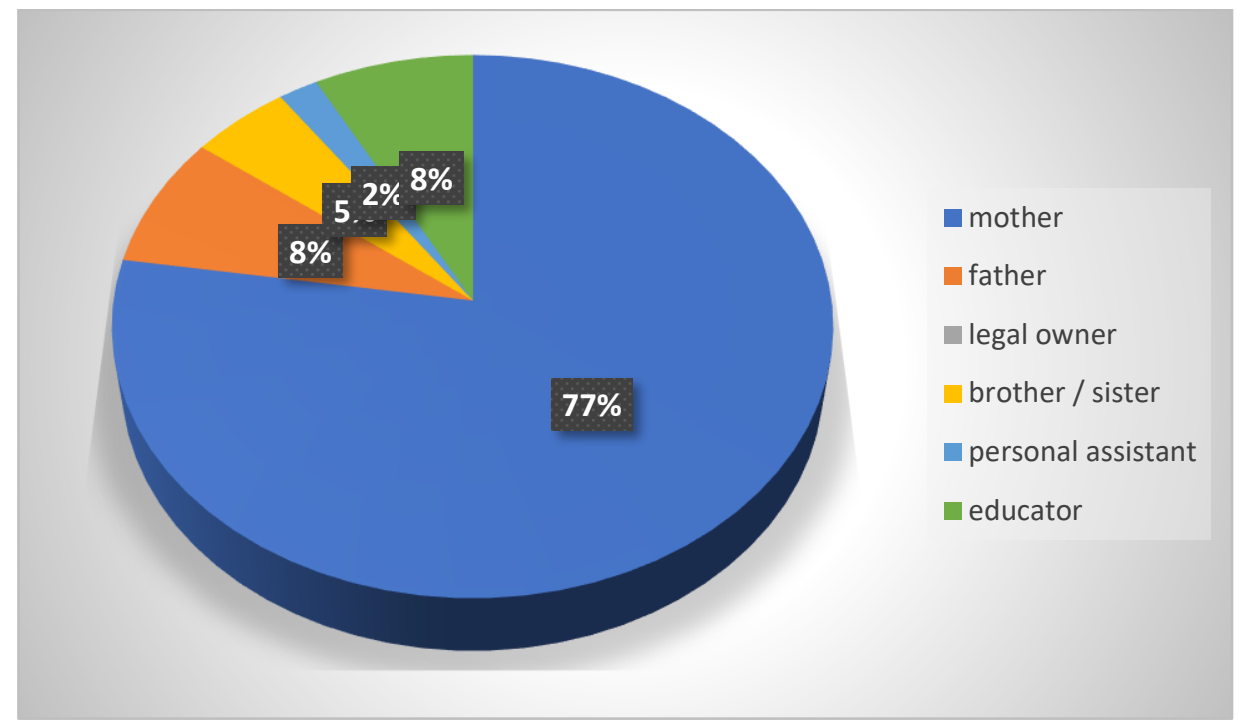

Fig. 1 Distribution by persons who completed the questionnaire

Next, we wanted to know the age categories in which people with Down syndrome fall in this survey. Thus, the highest share is represented by young people in the categories of 20-30 years and $31-40$ years with just over $29 \%$, respectively $28 \%$, still following the categories of children and adolescents, with a share of $16.5 \%$ children under 8 years, $12.6 \%$ between $8-14$ years and $9.7 \%$ those between 15-19 years. The lowest percentage is occupied by people over 40 with $4 \%$.

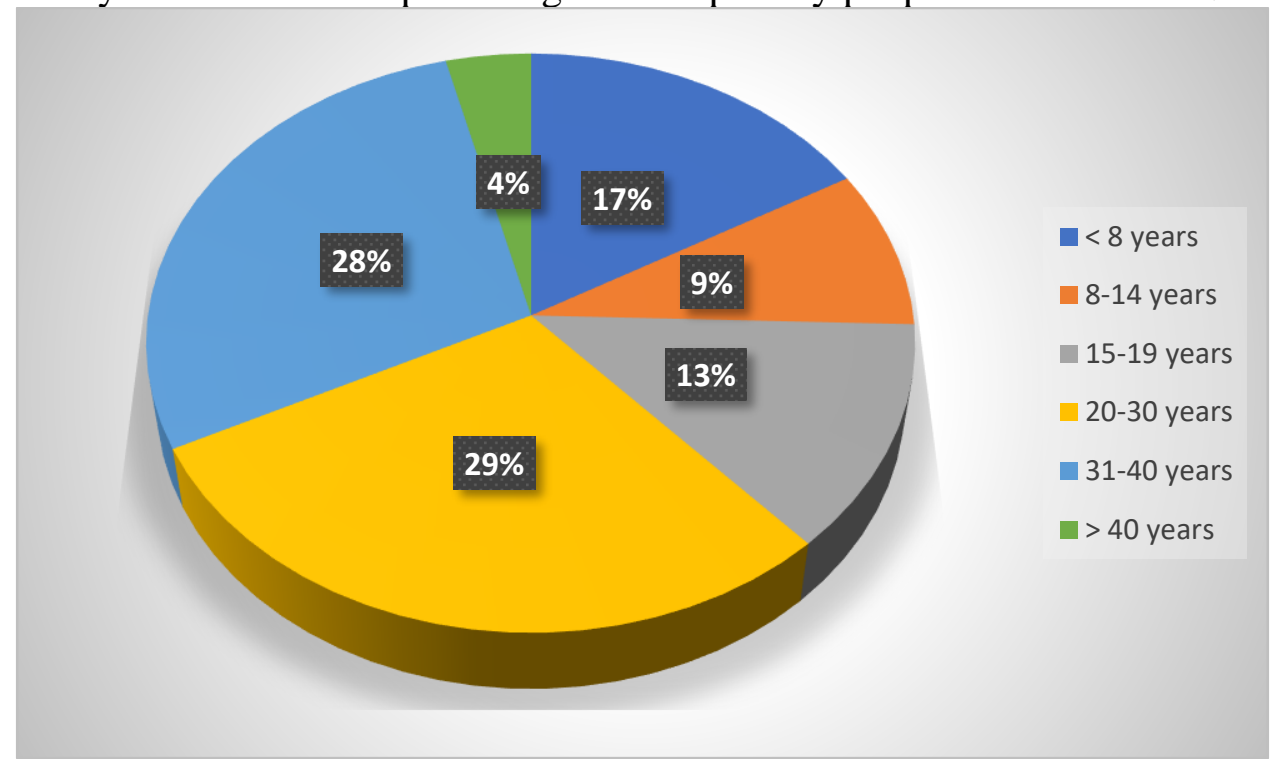

Fig. 2 Age distribution of people with Down syndrome

The next question analyzed the respondents' opinion on the use of sport as a method of social inclusion. With a proportion of $99 \%$, they agreed with this idea because the values that sport transmits are deeply consistent, in order to establish inclusive societies, focusing on the responsibility of creating an atmosphere that promotes sport as a means of social inclusion. Why is sport considered an element of social integration? Because through a sports activity, children with DS come into contact with other people, find out new information, find out what teamwork, competition and devotion are. 


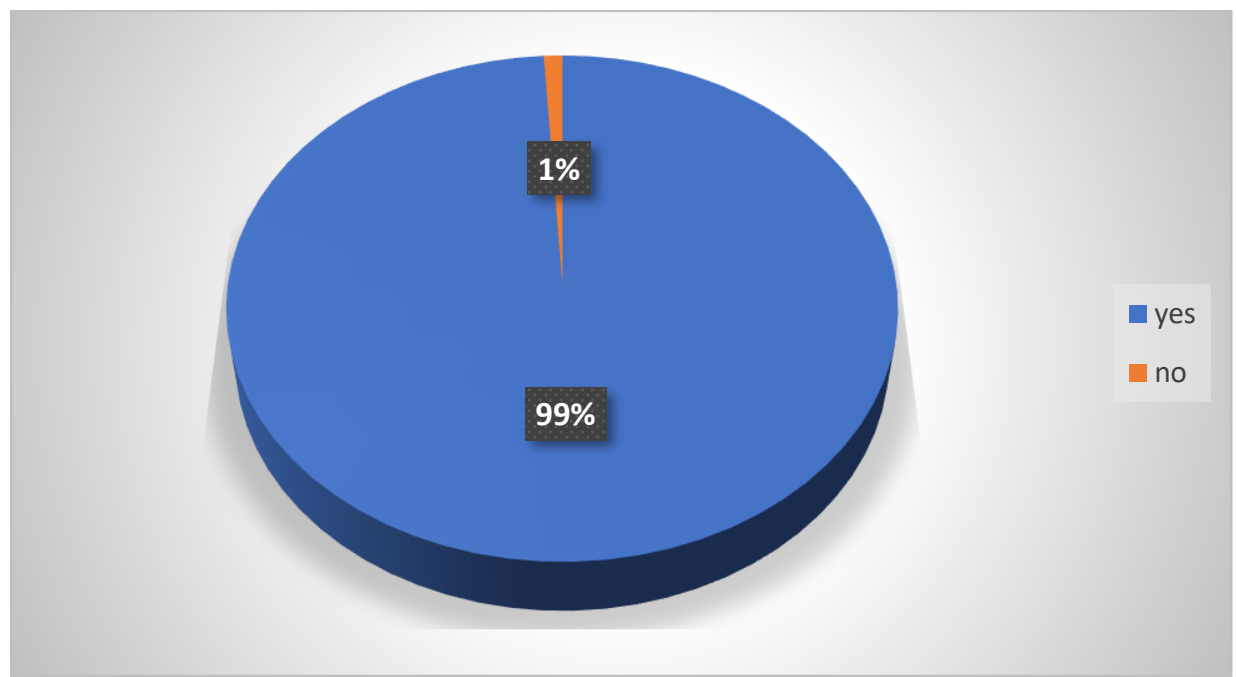

Fig. 3 Distribution according to the use of sport as a method of social inclusion

Regarding the practice of sports activities by people with Down syndrome, there are no negative cases, which is gratifying because we already know the effects that sport has on various aspects of people with disabilities. Thus, the majority of $40 \%$ practice sports twice a week, $29 \%$ do so once a week, and $26 \%$ sporadically. A percentage of $1 \%$ includes people who do sports at least twice a month.

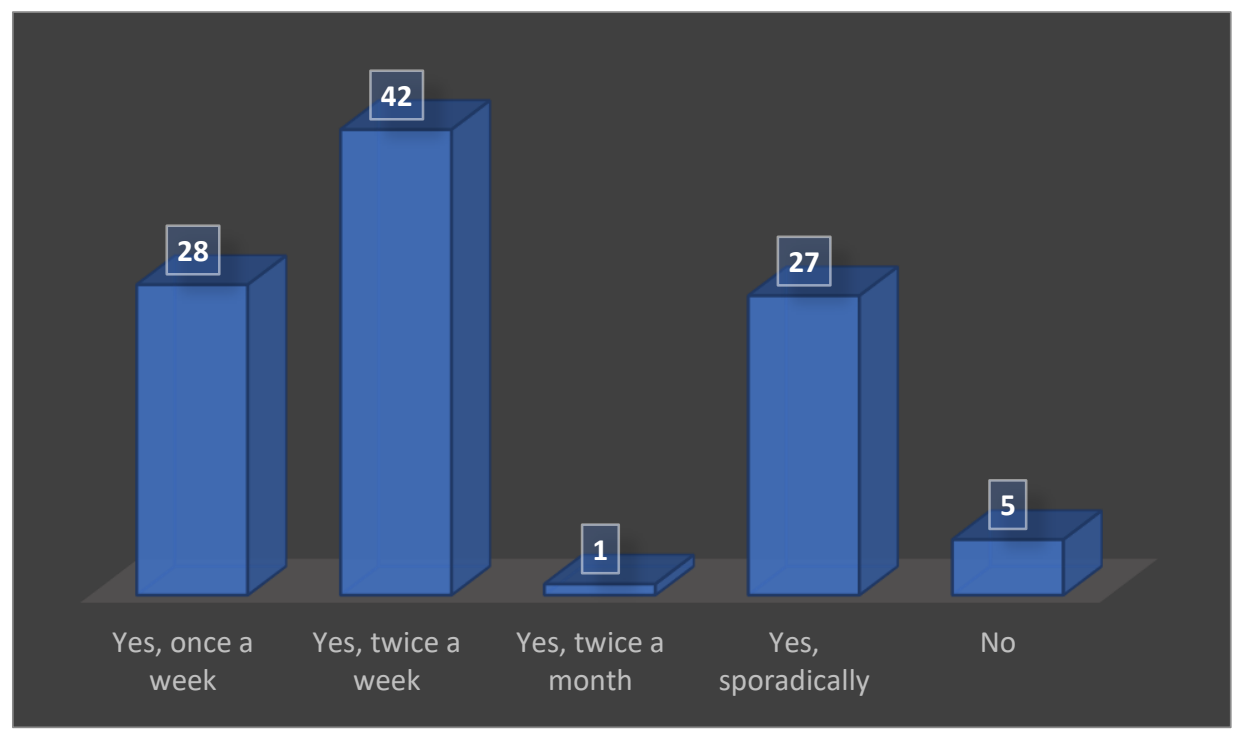

Fig. 4 Distribution according to the frequency of practicing sports activities

From the sports practiced by people with Down syndrome, swimming is in the first place, with 32 practitioners, followed by basketball and athletics with over 20 practitioners, and football and horseback riding are also present. Also, in the other category, various other sports were listed such as tennis, skiing, karate, roller skating, dance sports, gymnastics, fitness, climbing, volleyball, fencing, skating, rugby, but in very small proportions, being preferred depending on of each person's sports skills. 


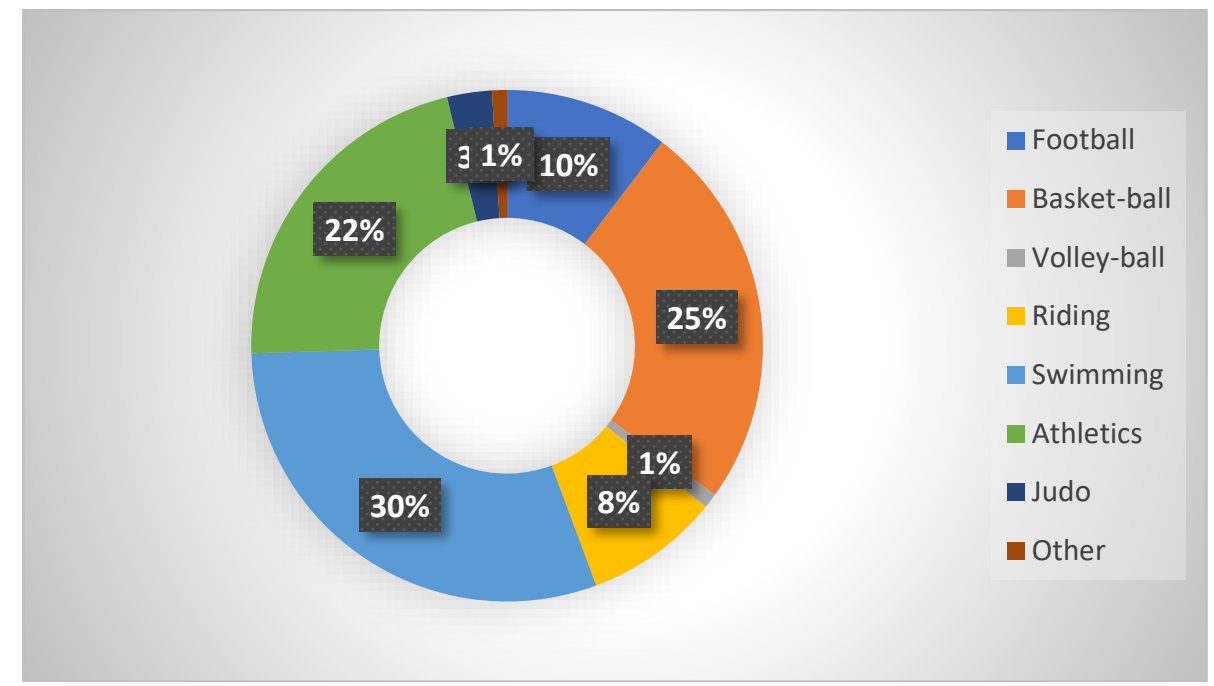

Fig. 5 Distribution according to the sports practiced

Since a large proportion of the people surveyed are either children or adolescents, we wanted to know if their wishes were taken into account when choosing sports activities. Over $90 \%$ of people with Down syndrome responded in the affirmative, considering that it is very important to take this into account, because people with disabilities have special needs and feel the need for independence, group membership and acceptance in society.

Sport creates the framework for establishing contacts between people who have the same needs and problems and helps to make new friends. By interacting with other people who face the same type of difficulty on a daily basis, people with disabilities can understand that they are not alone and can easily share their experiences.

Often, people with disabilities have low self-esteem and are prone to depression and isolation, but physical activity can restore their ability to feel valued.

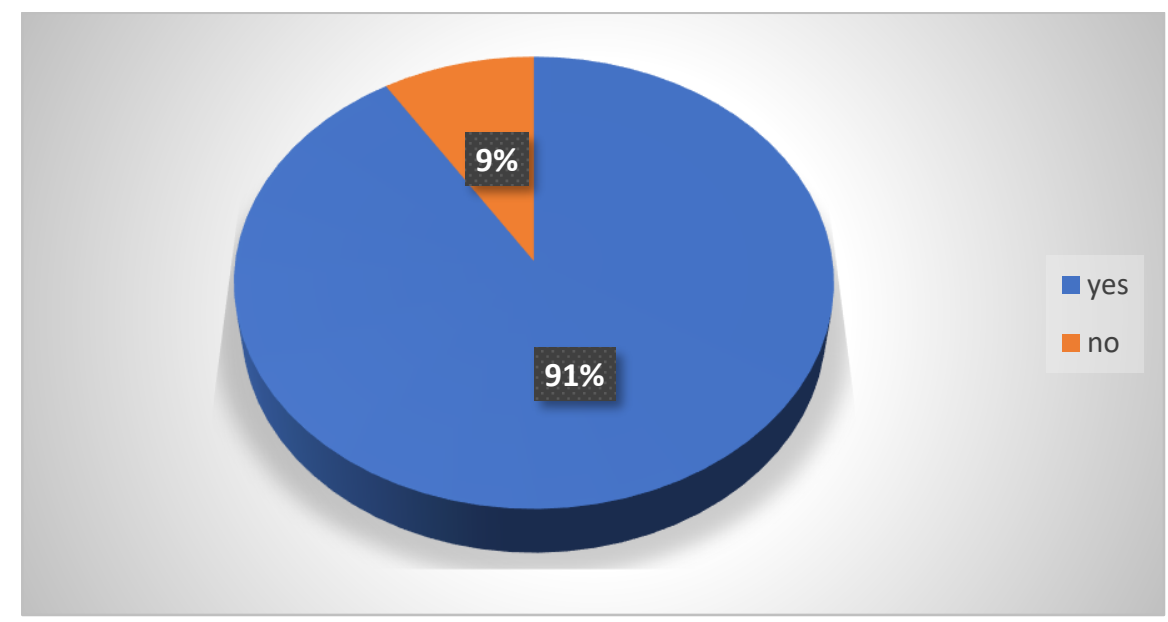

Fig. 6 Distribution according to the wishes of people with DS

The next question is one with evaluation scales, and analyzes whether the sports activity is adapted to the abilities of people with Down syndrome, following scales from 1 to 10 , where 1 means never, and 10 always.

As can be seen in the attached graph, the answers varied, each scale having a small percentage of respondents, but the majority is the scale marked with 10 , with a percentage of over $62 \%$ according to which sports activities are adapted to the abilities of people with DS. 


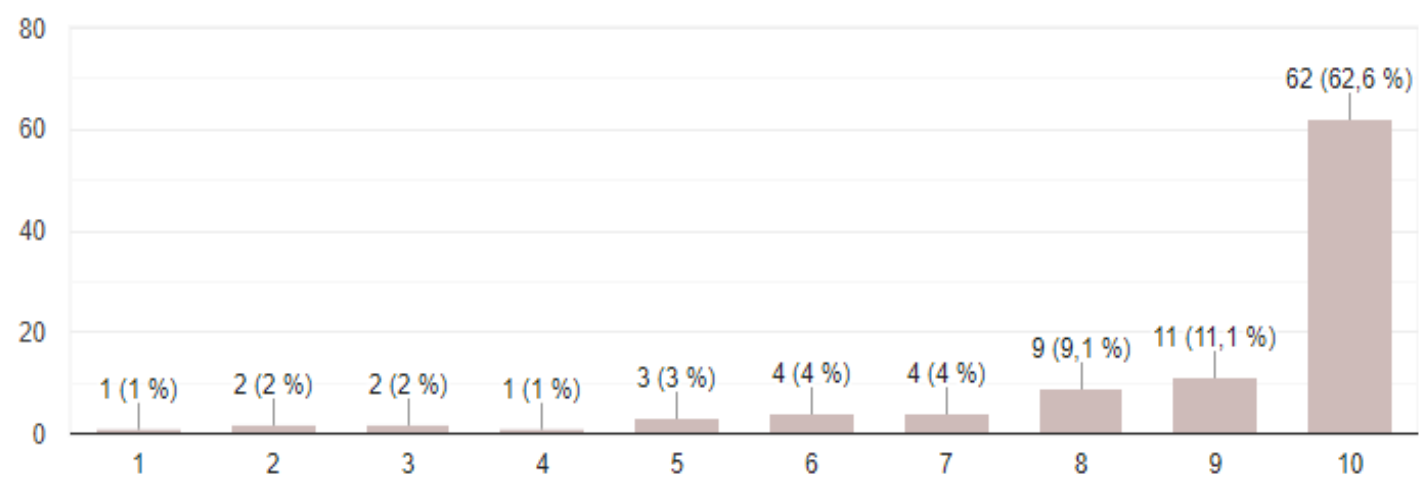

Fig. 7 Distribution according to the correlation between sport and skills

Regarding the practice of different motor activities, people with DS do this in a framework with people with or without disabilities $(68 \%)$, people with disabilities $(32 \%)$ and people without disabilities (16\%).

Currently, due to the progress of medicine and the study of this disability, people with DS can play sports adapted to people with disabilities. Like in ordinary people, people with disabilities can talk about mainstream sports and performance, there are domestic and international competitions and even Olympics, which have led to increased respect and admiration from ordinary people.

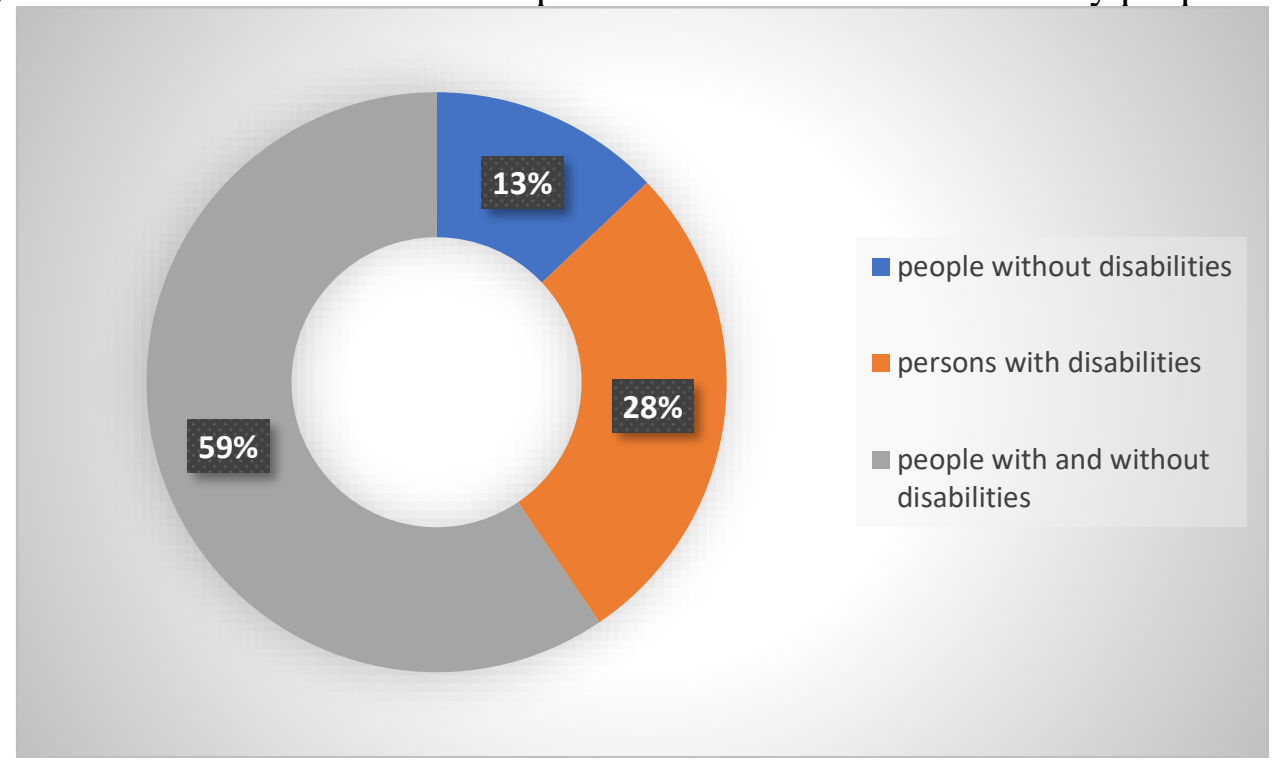

Fig. 8 Distribution according to the people with whom the sport is practiced

In a percentage of almost $80 \%$ people with Down syndrome prefer to practice sports activities in the context of recreation or leisure. Sports-recreational activity is a necessity that largely conditions the required performance. Through its role in society, recreational sports activities go beyond the dimensions of leisure activities, being part of the extensive training and educational program for people with disabilities for work and social life.

The entire range of sports-recreational activities, organized for the purpose of strengthening, compensation, relaxation and leisure, is experiencing an increasing expansion.

The next context for carrying out sports activities is that of competitions, an area that has seen an increasing development, with numerous competitions for people with disabilities, but also for recovery purposes. 


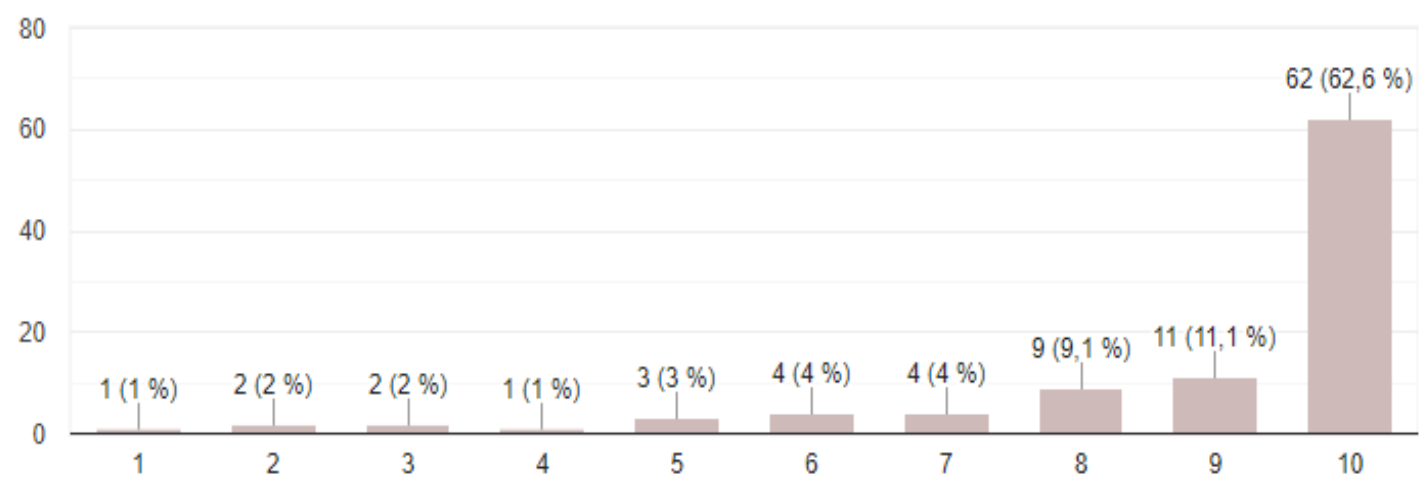

Fig. 7 Distribution according to the correlation between sport and skills

Regarding the practice of different motor activities, people with DS do this in a framework with people with or without disabilities $(68 \%)$, people with disabilities $(32 \%)$ and people without disabilities (16\%).

Currently, due to the progress of medicine and the study of this disability, people with DS can play sports adapted to people with disabilities. Like in ordinary people, people with disabilities can talk about mainstream sports and performance, there are domestic and international competitions and even Olympics, which have led to increased respect and admiration from ordinary people.

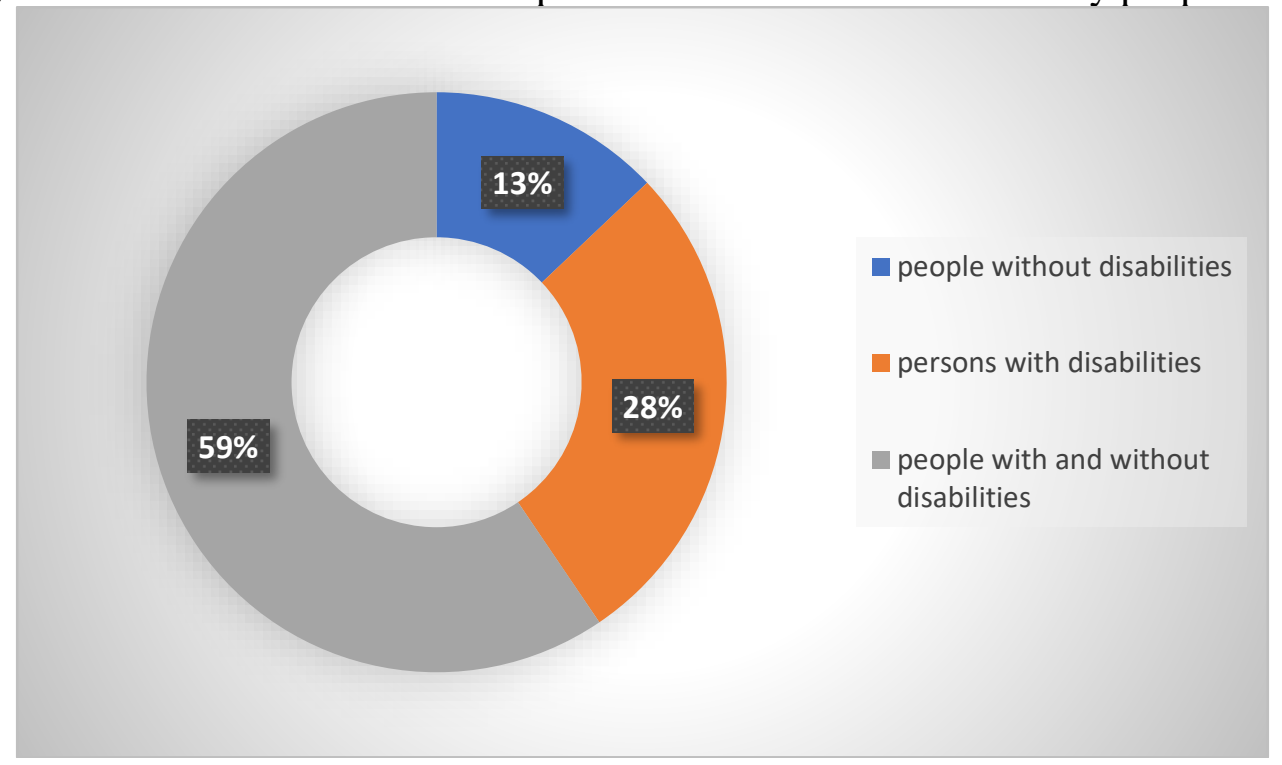

Fig. 8 Distribution according to the people with whom the sport is practiced

In a percentage of almost $80 \%$ people with Down syndrome prefer to practice sports activities in the context of recreation or leisure. Sports-recreational activity is a necessity that largely conditions the required performance. Through its role in society, recreational sports activities go beyond the dimensions of leisure activities, being part of the extensive training and educational program for people with disabilities for work and social life.

The entire range of sports-recreational activities, organized for the purpose of strengthening, compensation, relaxation and leisure, is experiencing an increasing expansion.

The next context for carrying out sports activities is that of competitions, an area that has seen an increasing development, with numerous competitions for people with disabilities, but also for recovery purposes. 


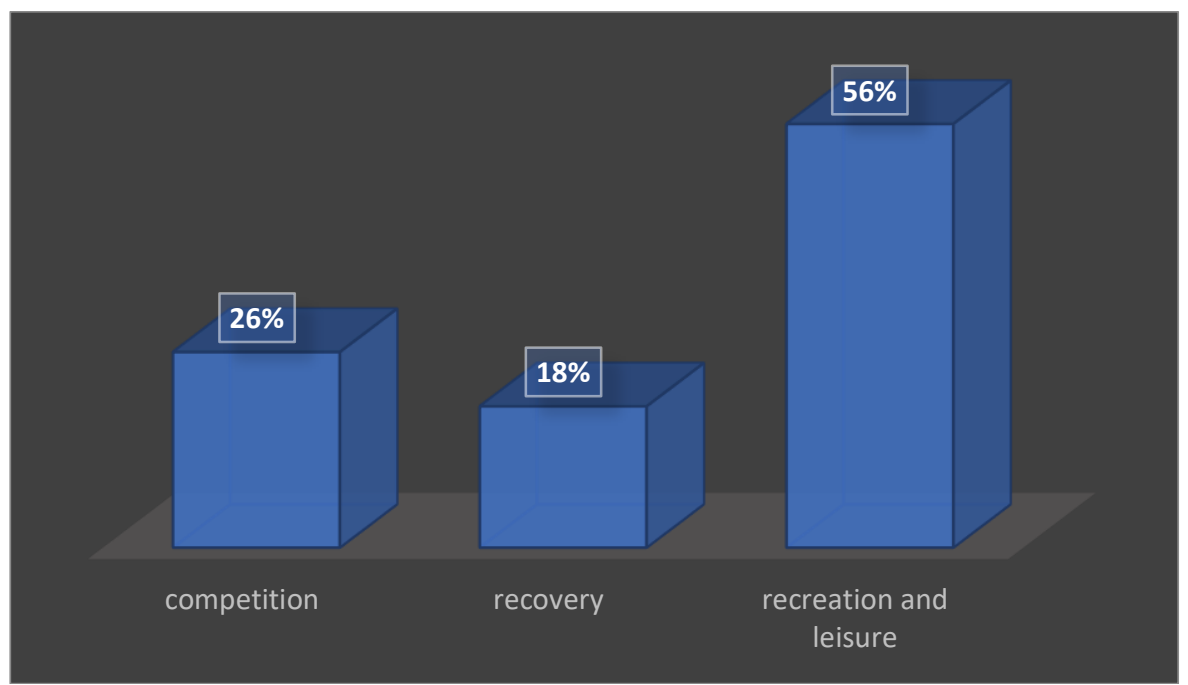

Fig. 9 Distribution according to the context of sports activities

To the question "On a scale of 1 to 10 , how much do you agree with the statement that sport can help a person with DS to improve their social inclusion?" 10 rating scales were set from 1 (not at all) to 10 (very much).

Thus, all respondents largely agreed, with a percentage of over $83 \%$ that sport is an important factor of social inclusion for a person with Down syndrome.

The incredible possibilities of people with disabilities, as well as their permanent desire to overcome their own performance, corroborated with the desire for competition, made the attitude of motor activities to be reoriented to sports adapted to people with disabilities. As for ordinary people, also for people with disabilities we can talk about mainstream sports, as well as highperformance sports, with domestic and international competitions and even Olympics.

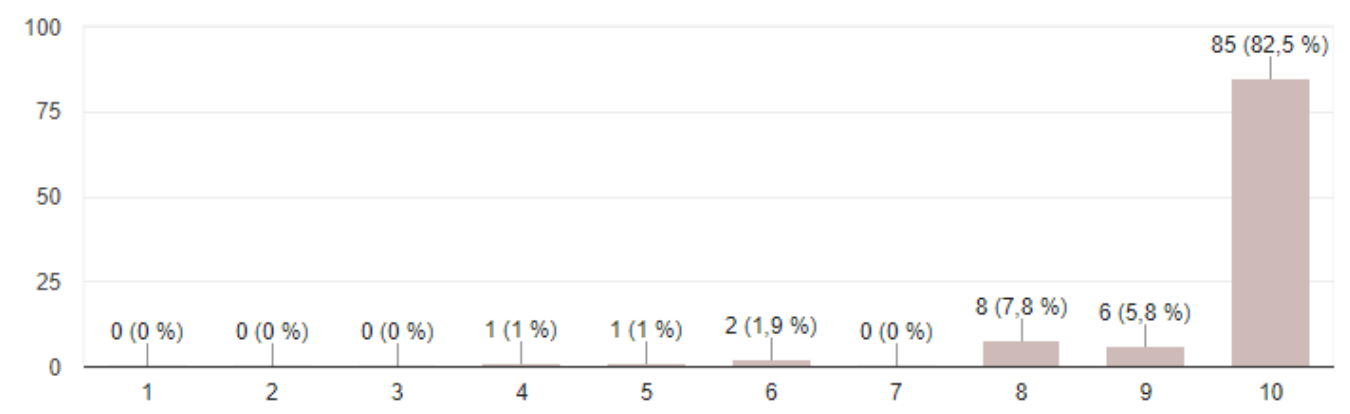

Fig. 10 Distribution after improving social inclusion through sport

The most important results that can be achieved when a person with Down syndrome practices sports activities, first of all are related to personal development: self-esteem, physical condition and autonomy, improvement of quality of life, improvement of physical condition, improvement of social condition or simply for fun.

On equal terms with other members of the community, people with Down syndrome must be able to enjoy full and equal rights, both in children and adults. This includes the opportunity to participate fully in the life of the communities to which they belong. 


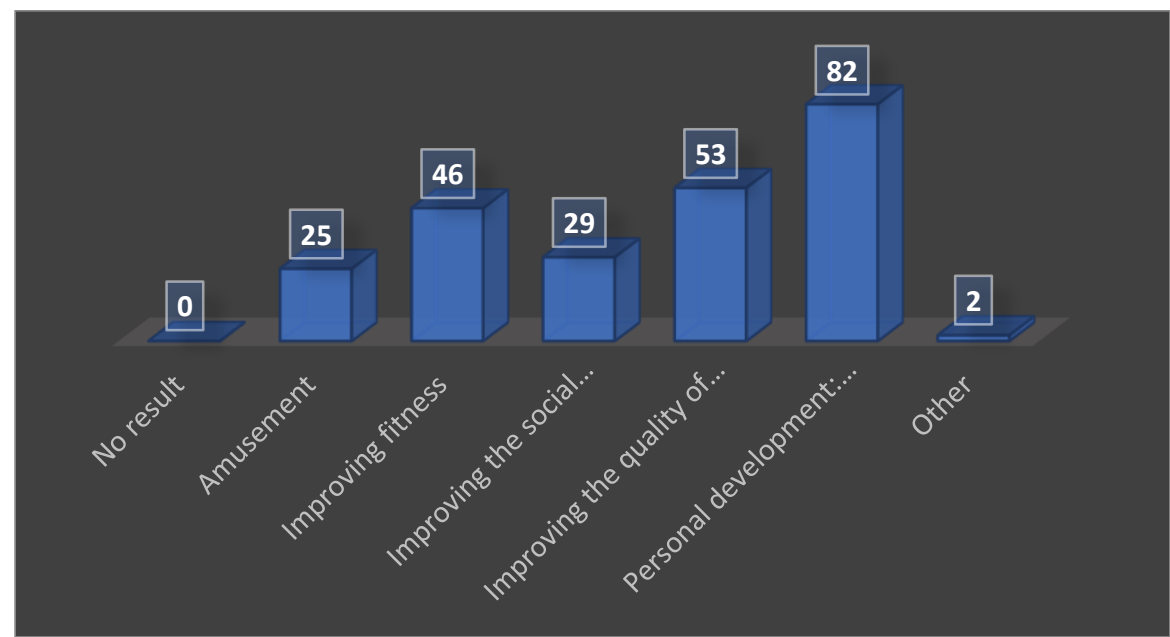

Fig. 11 Distribution according to the results obtained through sports

The next question was to find out the share of people who benefit most from inclusive sports. With a percentage of over $62 \%$, it is considered that everyone benefits, coaches, people without disabilities and those with disabilities.

The success of creating full social inclusion lies in the understanding between parents and coaches on a common vision, so that they can be resources in support of inclusion. Supporting the inclusion process means accepting diversity and taking on an important role in the lives of people with disabilities. The next category that benefits from inclusive sports is certainly the person with disabilities, sport creates the framework for establishing contacts between people who have the same needs and problems and helps to make new friends.

By interacting with other people who face the same type of difficulty on a daily basis, people with disabilities can understand that they are not alone and can easily share their experiences. Often, people with disabilities have low self-esteem and are prone to depression and isolation, but physical activity can restore their ability to feel valued. Physical activity is disconnecting, being a suitable way to spend free time.

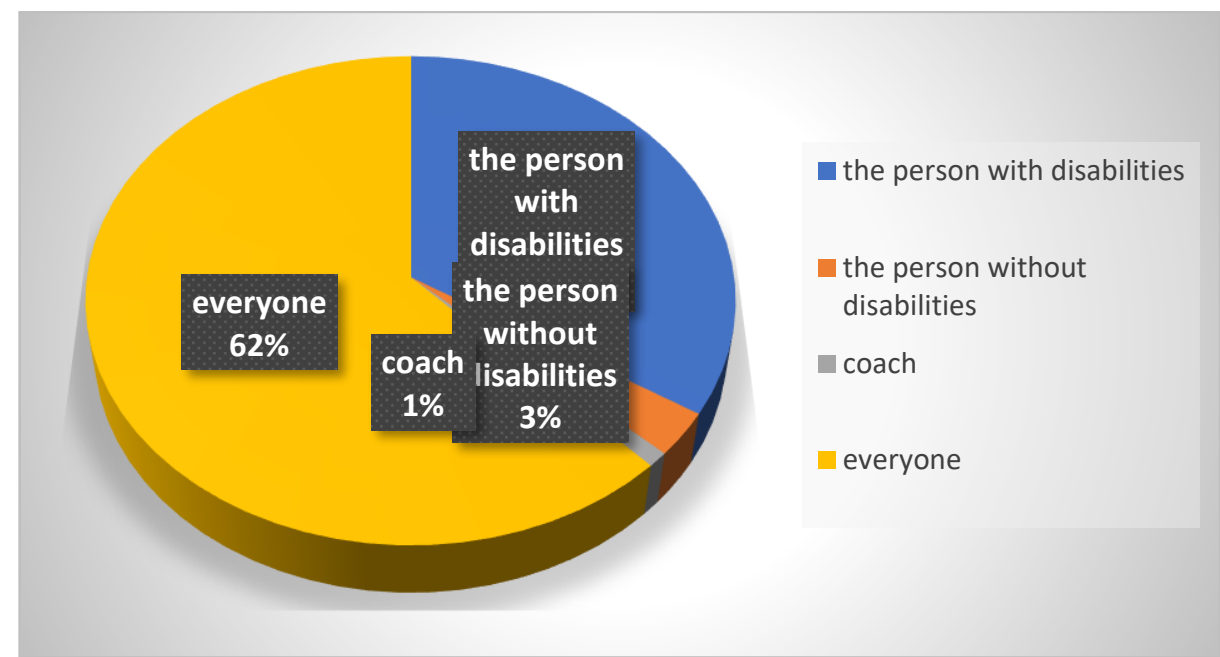

Fig. 12 Distribution according to the beneficiaries of inclusive sport

Certain fears that may exist for the legal representatives of people with DS are usually non-existent for most respondents, and this is because it has been understood that the most important thing these children need is independence. 
Only $1.9 \%$ of respondents considered that their involvement in sports activities is risky and that they are afraid to approve their participation in general activities (not organized especially for people with Down syndrome). There is, of course, a small percentage of people who are concerned about these issues.

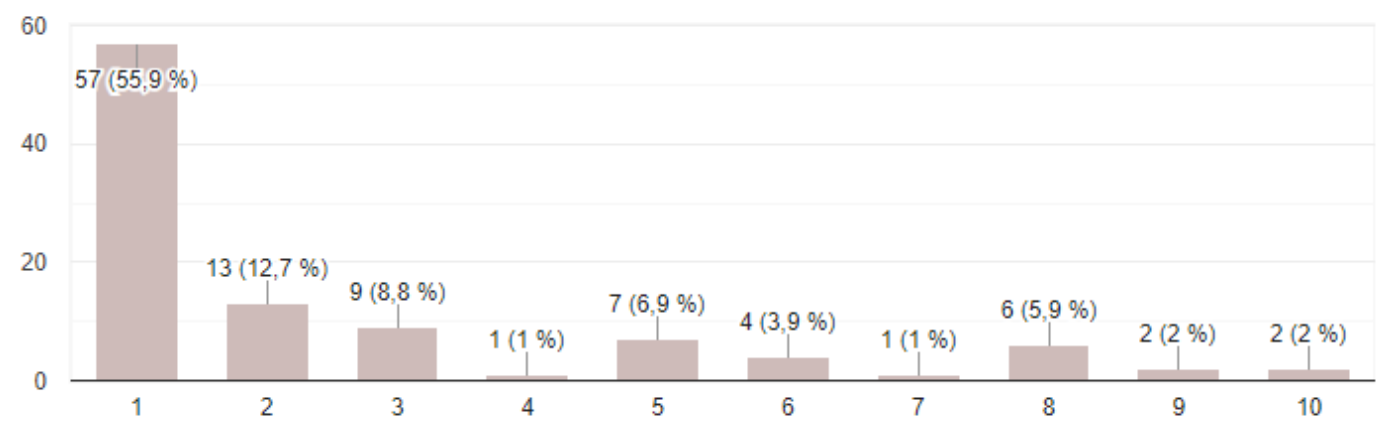

Fig. 13 Distribution according to fears / concerns regarding the person with DS

The next question continues the discussion analyzed in question 13, namely, the majority, representing 48 respondents out of a total of 104 said they have no fears for the participation of these people in sports activities.

From here we can see that these disadvantaged people in many activities are beginning to integrate much better into daily activities. This effort is also due to the people responsible for their integration into the community.

Next, analyzing the answers, we noticed that 29 of the respondents are worried about the behavior of the other participants in activities towards people with this affection.

In addition to these fears, 11 respondents believe that participants with Down syndrome would be intimidated and may be afraid of other participants, which has a negative impact on their morale. A large proportion of respondents (33 out of 104) also believe that frustration with other participants could occur in people with this syndrome. Only one respondent believes that people with Down syndrome could not keep up and should be helped.

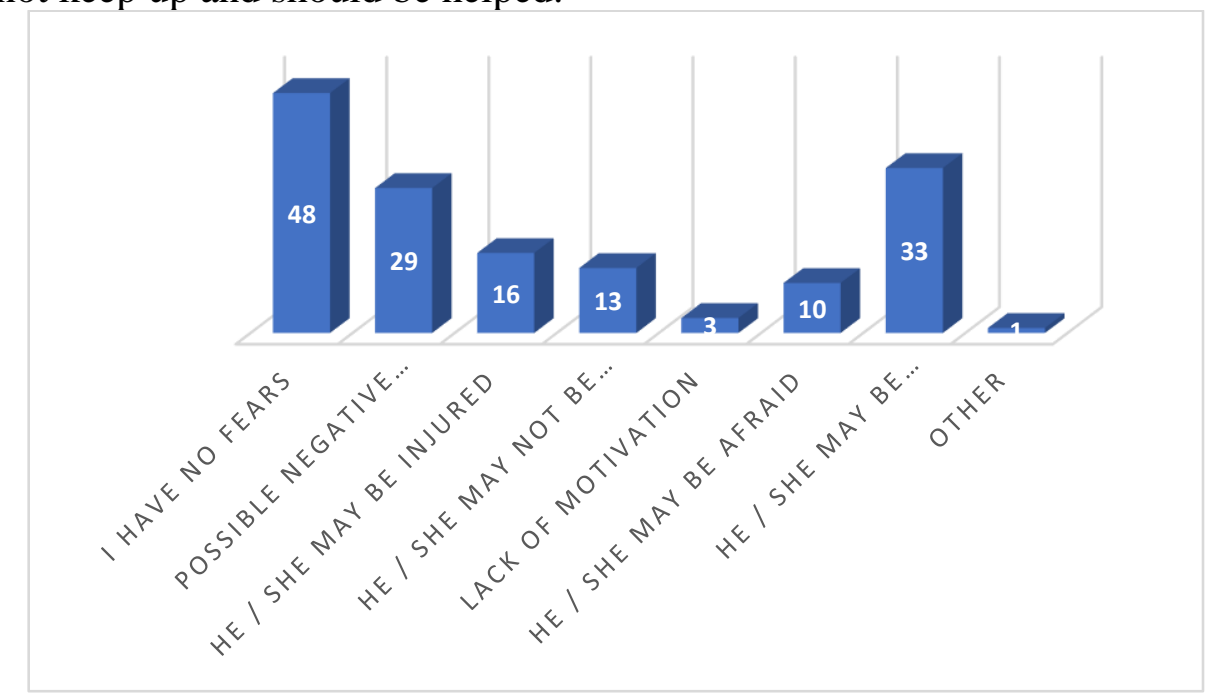

Fig. 14 Distribution based on fears of people without disabilities

When we talk about the involvement of people with Down syndrome in inclusive sports activities, 16 respondents out of 100 believe that there is no obstacle in their involvement in this kind of activities. On the other hand, 5 respondents consider that their lack of time could be an obstacle, and 4 respondents consider the lack of motivation as another obstacle. 
Taking into account the type of facilities needed to carry out these activities, 34 respondents consider that the distance to these facilities and their lack is a major obstacle. Another obstacle considered by 14 respondents to be important is the lack of communication and information on sports opportunities. On the other hand, taking into account the fact that people with Down syndrome need specialized help in carrying out these activities, the lack of qualified staff is considered an obstacle of 43 respondents. Also, the lack of regulations and competitions adapted to the physical abilities of people with Down syndrome is considered an obstacle by 12 respondents. 3 of the respondents consider that the lack of a complete diagnosis and medical reports on the physical abilities to which a person with Down syndrome can be subjected is an obstacle. The incompetence and lack of involvement of the public administration in the integration and protection of these disadvantaged people is considered a major obstacle by 35 of the respondents. On the other hand, 7 respondents consider that the family itself is an obstacle for reasons of family overprotection. Among the recorded responses, a large proportion considered a lack of awareness of the general public, being reported by 20 people.

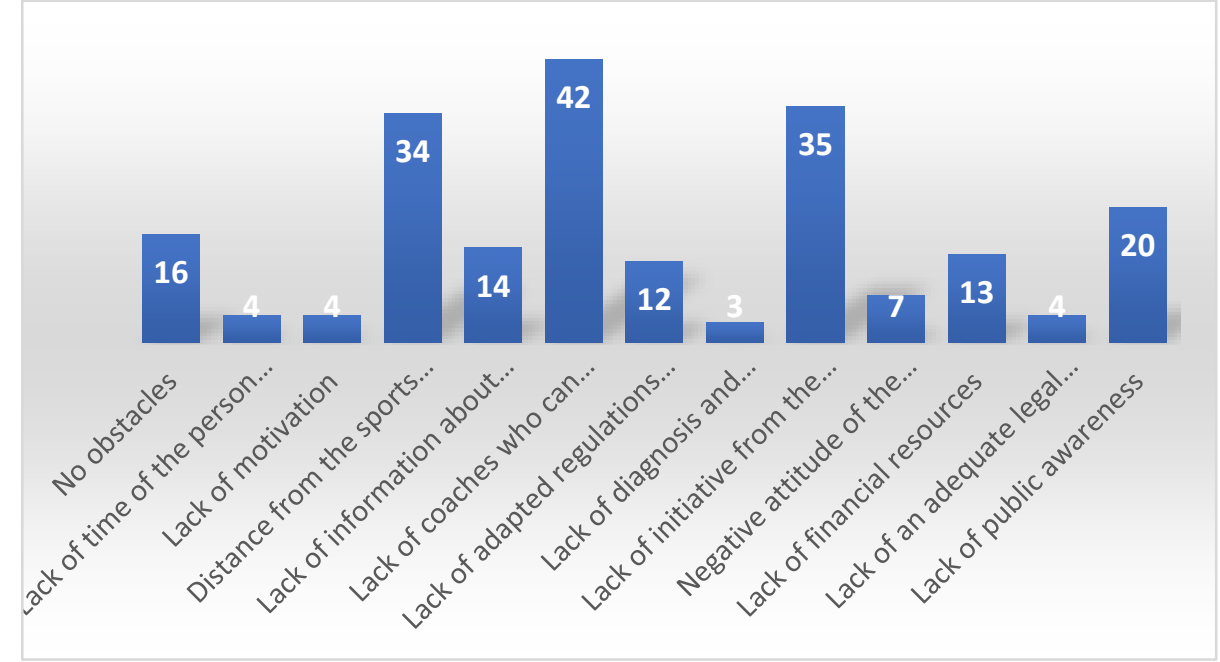

Fig. 15 Distribution according to obstacles

To this question, it was wanted to quantify the most efficient methods of carrying out sports activities. Among the most indicated were the activities adapted to the needs and skills of people with Down syndrome representing a percentage of $48 \%$ of all respondents. The next method considered effective is inclusive activity, registering a percentage of $34.3 \%$ of the total respondents. Among the most inefficient methods is the separate activity recording only $3.9 \%$ of all respondents. This type of activity creates an even greater barrier between people with down syndrome and the rest.

This question was also asked to explain the chosen answer, among the most important being: "By adapting the activities we reach a level of balance, which then leads to balanced results, a harmonious development and implicitly to inclusion achieved in stages", "Because both can learn from each other and a connection is created between them, they can learn to communicate to be good for all", "People with DS learn by imitation, they need an example given by another ordinary peer in the same age group. Inclusion is very important for the emotional support of the child with DS.” 


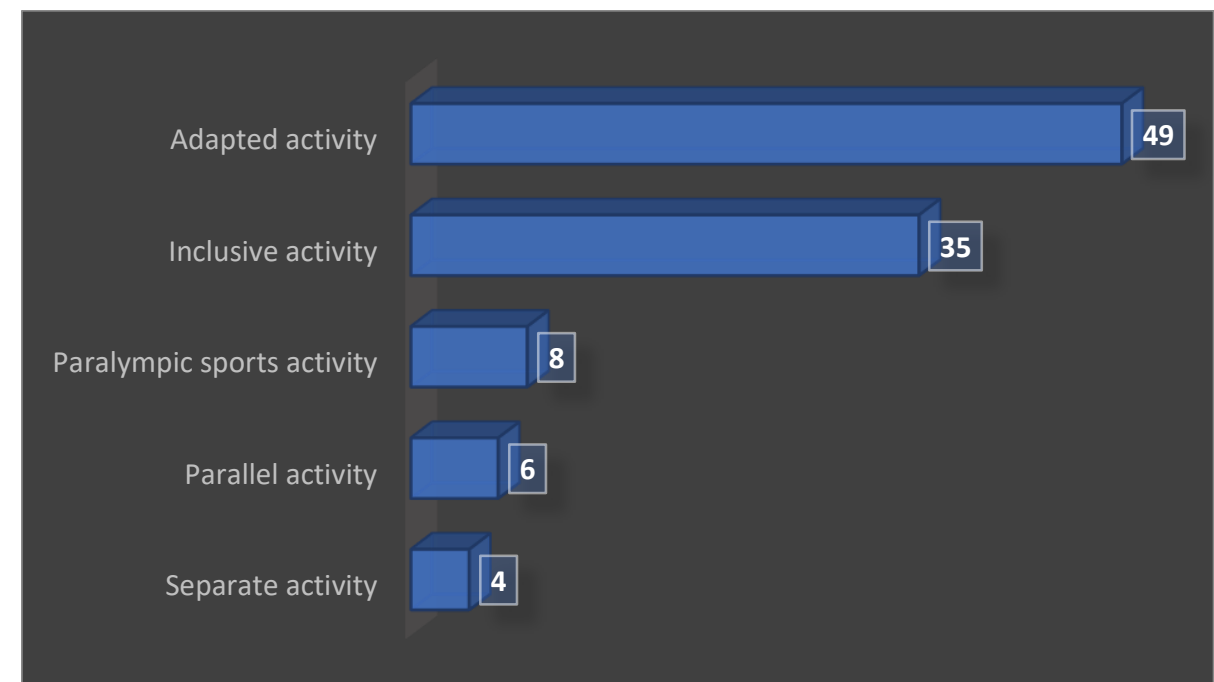

Fig. 16 Distribution according to a more efficient context in order to teach sports activities

When asked what type of communication the coach should use in interacting with people with Down syndrome, the best option (80 respondents) was to use practical examples and sports demonstrations. This helps to build confidence and create a strong motivation to practice sports. Also, when people with Down syndrome who do not understand issues related to sports activities, separate instructions should be created to help them understand these issues, a method considered to be beneficial by 41 of the respondents.

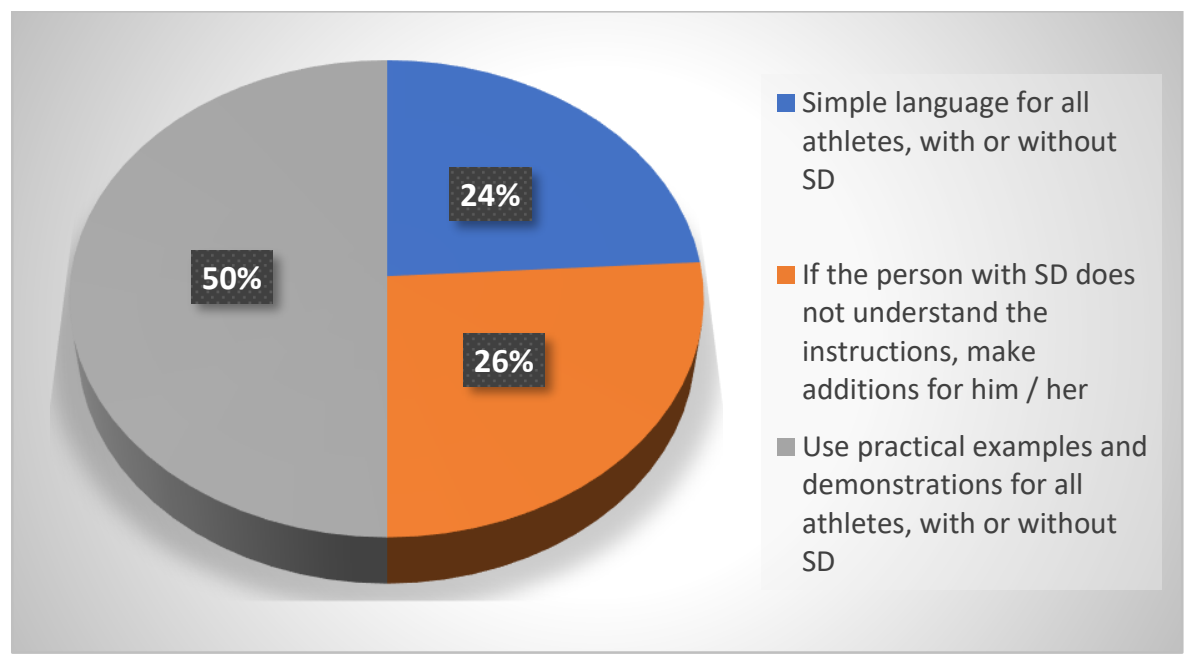

Fig. 17 Distribution according to the type of communication used by the coach

In this question we wanted to highlight the aspects that must be taken into account by a coach in the learning process with people with Down syndrome. Thus, first of all, the coach must show understanding, then attention to another equally important factor, and be motivated to be able to transmit this state to the athletes as well. Communicating with these people goes through a rather difficult path, encountering various difficulties. Specialists in the field mentioned that the knowledge of the coaches about the peculiarities of socialization of these athletes can contribute to facilitating the process appointed. 


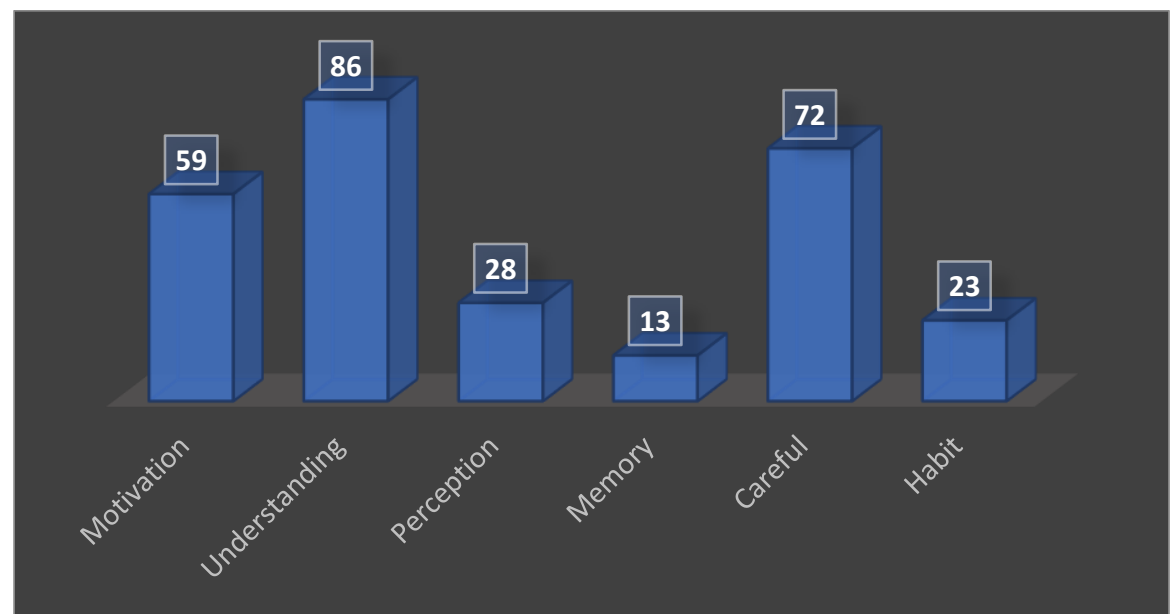

Fig. 18 Distribution according to the aspects taken into account in the learning process

In the learning process of people with Down syndrome, the most important aspects to be taken into account are the safety of these people, an aspect considered very important by 83 respondents, followed by their determination, which goes hand in hand with their motivation, being considered important by 71 respondents.

Other important aspects that must be taken into account are the dignity and expectations being considered crucial by 49 respondents, respectively 35 respondents.

Sport can improve the health issues associated with Down syndrome (hormonal and glandular disorders, hearing and vision loss, as well as heart issues) that can worsen in the absence of exercise. In addition to the physical benefits, sport has a therapeutic role in restoring certain body functions, regulating the imbalance in the body and stimulating personal resources.

Next, we wanted to know the most important elements that a coach must do in the process of learning with athletes with Down syndrome.

Thus, 69 of the respondents consider that the coach must be supportive with athletes, supporting them at every step. The lack of marginalization is considered by 69 respondents as another element to help these children in their activities. The least important were the organization of high-quality training and competitions.

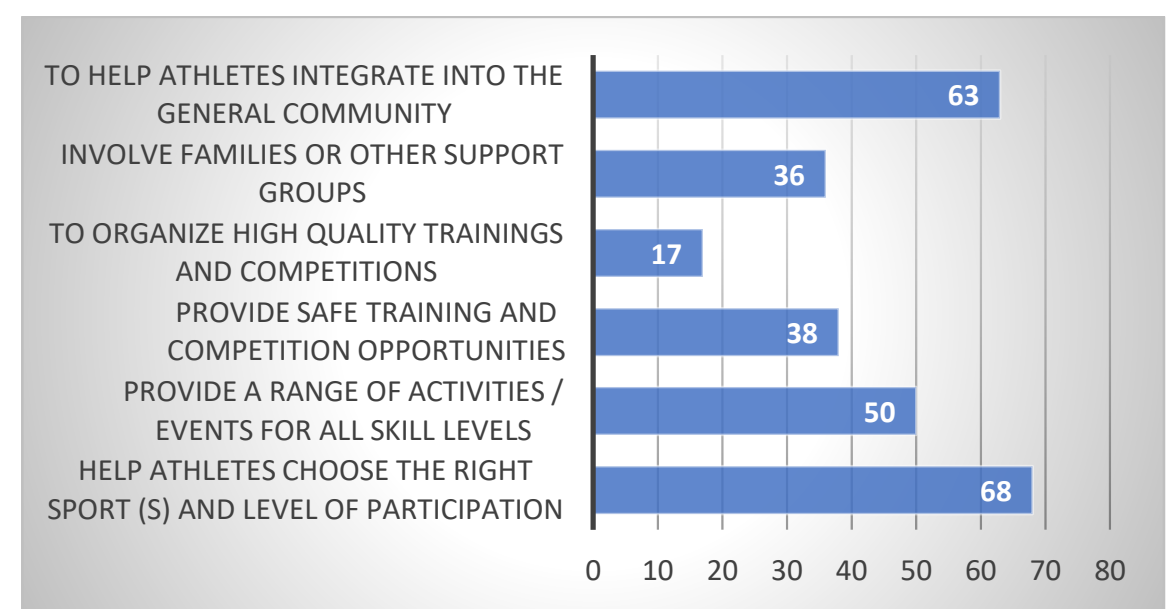

Fig. 19 Distribution according to the importance of the things done by the coaches

When it comes to respondents' confidence in the ability of people with disabilities to practice sports, most of the respondents ( $74.3 \%$ of them) said that their practice helps to improve the health and mood of people with Down syndrome. $54.3 \%$ of respondents reported that the practice of sports activities would greatly help the process of including people with Down syndrome in society. 
Another way to practice sports activities is for fun and relaxation, an option chosen by $23.8 \%$ of respondents, and $29.5 \%$ indicate that these sports activities can also be practiced at the competition level.

\section{Conclusions}

People with disabilities must have physical, informational and communicative access to the products, the services and programs that the community makes available to its members. In a fast-paced world, through education in general and sports activities in particular, we can increase acceptance of change and openness to the other (Cosma, Nanu, Burcea, Barbu, \& Cosma, 2017). Therefore, there is requesting a change of attitude towards the issues and opportunities of active and effective involvement of people with Down syndrome in the community life, the renunciation of bias and stereotypes that consider these people as totally dependent on others (unable to perform activities and / or services useful to the community) and cultivating the principle of equality, diversity and inclusion that values the social and professional achievements / successes of everyone in the perception of community members.

We can note that out of a wide range of activities that can support the effective inclusion of people with disabilities in society, physical education and sports occupy a privileged place. Its practice by members of a community brings them self-confidence, a sense of identity and belonging, physical and mental wellbeing. People with Down syndrome show deficiencies of physical development during growth and various delays in relation to the chronological age, going through the stages of early motor development in a slow manner during childhood, that is also reflecting on the other stages of life. All these peculiarities affect the development and the harmonization of movements with the nervous control in order to properly perform a planned action composed of more movements and steps, as it is a sportive activity, especially one carried out at team level. Practicing sport aims at planning the execution and the movements sequencing. Physical activities are reflected in activities of daily living, directly involved in the development of the autonomy of the people with Down syndrome, no matter the age. The visual, spatial and coordination problems become more obvious, as time goes on.

The fine and gross motor skills must be enriched and practiced in order to improve the physical development together with the integration of the mental image and of the visual and spatial abilities in their movements.

People with Down syndrome have also problems with the sensorial integration and that is why, they are recommended to take part in the activities of improving the sensorial integration especially in order to increase their inclusion and social adaptation.

People with Down syndrome must practice their motor skills in order to feel better and to have a better and more beautiful life.

Developing fine and gross motor skills, improving visual and auditory skills, improving attention, improving coordination and pace of movement, increasing body balance and last but not least, improving autonomy are amongst the objectives of playing sports. Concrete experiences are the best source of effectiveness, they are based on authentic actions (Cosma et al., 2020).

People with Down syndrome need a bigger support than the ordinary people of the same age (Haveman et al., 2011) because of the decline of the cognitive behaviour and the adaptive skills at a very early age with impact on the independent functioning (Carmeli \& Iman, 2014; Strydom et.al., 2013). These people often present a debut of the early aging characteristics in comparison with the general population (Lin et. al, 2011). Thus, the health promotion by doing initiatives that encourage o bigger participation at the physical activities may be an essential pylon the moment there are involved people with Down Syndrome (Ruiz-González et. al., 2019).

It is very important that these physical/sportive activities start as soon as 
possible, the activity must be continuous and supported by all actors involved: first of all, to be accepted by the people with Down syndrome, by their family members, and also by the community in which they live. The sportive activities should aim the maintenance of the psychomotor skills, also being taken into account the difficulties coped by the people with Down Syndrome and to propose themselves to try and overcome them, emphasizing the progress they register.

There are specific health issues that people with Down syndrome face, including (DSAgeing): heart disease/ valvular disorders, hypothyroidism, celiac disease/ gastrointestinal disease, type I diabetes, seizures/ epilepsy, hearing/ vision loss, obesity and lipid metabolism disorders and others. All of these ailments, as well as the limitations in practicing different sports they impose must be taken into account every time and in every activity carried out. One solution could be to develop sports activities especially designed for people with Down syndrome and even designing special types of sports and games, and certain adaptations of the existing sports to the specific situations in which people with Down syndrome are found. Independently of the group or team activities, an important learning tool is the use of digital resources such as didactic or video tutorials that can be easily made even at home.

In this respect, in order that sport becomes a way of life, the most suitable methods remain learning by doing, awareness the inclusion of people with Down syndrome, promoting professionals in this field, empowering family members as direct participants who can facilitate the change, involvement of different associations/entities that promote sport and provide digital training to the people with Down syndrome in using ICT tools, in order to be able to continue practicing in the comfort of personal home or even more, during the restrictions and lock-down periods caused by the Covid-19 pandemic.

The project this article belongs to also aims to design such a model of good practice example to be put into practice further on.

Acknowledgment
This article was developed in the framework of the Erasmus + Sport, Agreement "Sports activities for people with down's syndrome", No. 622121-EPP-1-2020-1-IT-SPO-SCP., implemented by the Langdon Down Oltenia Association - Teodora Educational Center, beneficiary: ASD Running Matera.

All authors contributed equally to this research.

\section{References}

Barbu, M. (2004). Istoria educaţiei fizice şi sportului. Craiova, Editura Universitaria.

Birrer, R. B. (2004). The Special Olympics athlete: evaluation and clearance for participation. Clinical pediatrics,43(9), 777-782.

https://doi.org/10.1177/000992280404300 $\underline{901}$

Carmeli, E. \& Imam, B. (2014). Health promotion and disease prevention strategies in older adults with intellectual and developmental disabilities. Frontiers in Public Health, 2 (31), 1-7. doi:10.3389/fpubh.2014.00031

Cosma, G., Nanu, M., Burcea, B., Barbu, D., \& Cosma, A. (2017). Pregătirea fizică în sportul de performanță. Craiova, Editura Universitaria.

Cosma, G., Chiracu, A., Stepan, R., Cosma, A., Nanu, C., Păunescu, C. (2020). Impact of coping strategies on sport performance. Journal of Physical Education and Sport, 20(3):1380-1385.

Daniels, G., Finning, K., Martin, P., \& Massey, E. (2009). Noninvasive prenatal diagnosis of fetal blood group phenotypes: current practice and future prospects. Prenatal diagnosis, 29(2), 101107. https://doi.org/10.1002/pd.2172.

Haveman, M., Perry, J., Carulla, L., Walsh, P., Kerr, M., Schrojenstein, H., Valk, L., ... \& Weber, G.(2011). Ageing and health status in adults with intellectual disabilities: Results of the European POMONA II study. Journal of Intellectual and Developmental Disability, 36 (1), 4960. doi: 10.3109/13668250.2010.549464

Lin, J., Wu, C., Lin, P., Lin, L., \& Chu, C. (2011). Early onset ageing and service preparation in people with intellectual 
disabilities: Institutional managers' perspective. Research in Developmental Disabilities, 32:188-193. doi: 10.1016/j.ridd.2010.09.018

Millar, A. L., Fernhall, B., \& Burkett, L. N. (1993). Effects of aerobic training in adolescents with Down syndrome. Medicine \& Science in Sports \& Exercise, 25(2), 270274. https://doi.org/10.1249/00005768199302000-00018.

Potter, H. (1991). Review and hypothesis: Alzheimer disease and Down syndrome-chromosome 21 nondisjunction may underlie both disorders. American journal of human genetics, 48(6), 1192-1200.

Ruiz-González, L., Lucena-Antón, D., Salazar, A., Martín-Valero, R., \& MoralMuñoz, J. A. (2019). Physical therapy in Down syndrome: systematic review and meta-analysis. Journal of Intellectual Disability Research, 63, 8, 1041-1067. https://www.sindrom-down.ro/wpcontent/uploads/2020/11/DSAGEING_Brosura.pdf

Skotko, B., Levine, S. \& Goldstein, R. (2011). Having a brother or sister with Down syndrome: perspectives from siblings. American Journal of Medical Genetics Part A 155A(10):2348-59.

Shivers, CM., Dykens, EM. (2017). Adolescent sibling of individuals with and without intellectual and developmental disabilities: Self-reported empathy and feelings about their brother and sisters. American Journal of Intellectual and Developmental Disabilities, 122 (1):62-77.

Strydom, A., Chan, T., King, M., Hassiotis, A. \& Livingston, G. (2013). Incidence of dementia in older adults with intellectual disabilities. Research in Developmental Disability. 34(6), 1881-5. doi:10.1111/j.1741-1130.2010.00253.x 